\title{
Cybersex With Human- and Machine-Cued Partners: Gratifications, Shortcomings, and Tensions
}

\author{
Jaime Banks' and Joris Van Ouytsel ${ }^{2}$ \\ ${ }^{1}$ College of Media \& Communication, Texas Tech University \\ ${ }^{2}$ University of Antwerp
}

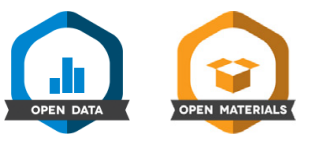

From social-network spambots and forensic chatbots to dating simulation games, sexual communication with machines is not uncommon in contemporary culture-however, it remains effectively a black-box phenomenon. There is little empirical research examining how sexual human-machine communication (HMC-S) is experienced, whether it is impactful, or whether it may be similar or different to human-human sexual communication. Advancing our understanding of those questions is vital in understanding the potential for machine partners to foster the health and welfare benefits, as well as the potential to have negative impacts. This study takes a first step in considering experiential parity or divergence by experimentally investigating 271 people's cybersex experience with a chat partner that was visually and textually cued as a human or a machine. Multimethod analysis suggests there may be no difference in gratifications from sex chat with ostensible machine versus human partners; however, participants seem to experience tensions between the gratifications and shortcomings of cybersex with machine-cued partners.

Keywords: cybersex, sexting, ontological categorization, sexual communication, sexual interaction illusion

Supplemental materials: https://doi.org/10.1037/tmb0000008\#supplemental-materials

From social-network spambots and forensic chatbots to dating simulation games and robot brothels, sexual communication with machines is not uncommon in contemporary culture-however, it is effectively a black-box phenomenon. Popular and critical discussions of its novelty (Nguyen, 2017), ethics (Eskins, 2017), and health implications (Cox-George \& Bewley, 2018) abound, but much less consideration is given to empirically understanding whether or how sexual human-machine communication (HMC-S)

Action Editor: Danielle S. McNamara was the action editor for this article. ORCID iD: Jaime Banks (iD https://orcid.org/0000-0002-7598-4337.

Disclosure and Acknowledgments: The authors have no conflicts of interest to report. The authors thank the chatbot developer (who wished to remain anonymous) for their contribution of the stimulus chatbot; the project would not have otherwise been possible.

Open Science Disclosures:

It The data are available at https://osf.io/n9df7/.

The experiment materials are available at https://osf.io/n9df7/.

Open Access License: This work is licensed under a Creative Commons Attribution-NonCommercial-NoDerivatives 4.0 International License (CCBY-NC-ND). This license permits copying and redistributing the work in any medium or format for noncommercial use provided the original authors and source are credited and a link to the license is included in attribution. No derivative works are permitted under this license.

Disclaimer: Interactive content is included in the online version of this article.

Contact Information: Correspondence concerning this article should be addressed to Jaime Banks, College of Media and Communication, Texas Tech University, Box 43082, Lubbock, TX 79409, USA. Email: j.banks@ttu.edu is experienced, is impactful, or how it compares to human-human sexual communication.

This gap in the research is noteworthy given the potential psychosocial benefits of human-machine cybersex for various types of users, especially those who are underserved or marginalized (Szczuka et al., 2019). These technologies allow individuals to explore and develop their sexualities in safer and more comprehensive ways than in other contexts (Döring, 2017). Studying cybersex gratifications is particularly timely as the market for cybersex chatbots (artificial agents that allow for textual forms of sexual communication) is expanding due to technological advances in artificial intelligence (AI). Specifically, producers of physical sex-enabled dolls are developing high-quality customizable AI companions that are offered as smartphone application and that are offered as stand-alone versions or that are integrated into their physical products (Coursey et al., 2019).

This study moves toward bridging that knowledge gap by experimentally examining sex-chat participants' experiences as a function of the chat partner's perceived ontological category - the prototypical class of entity to which a given agent is thought to belong. Shared category-membership (i.e., humans among themselves as a group) is understood as a heuristic for self-similar experience and implicit norming, and discrete category-membership (i.e., humans vs. machines) makes salient divergent origins, autonomies, and emotional and intellectual capabilities (Guzman, 2020). Therefore, it is possible that the experience of chatting with a machine partner could be procedurally and effectually different than with a human partner (cf. Ho et al., 2018). Conversely, humans are known to preconsciously engage machines as social actors when the technology 
exhibits even minimal linguistic, aural, and/or visual cues similar to those of humans (cf. Nass et al., 1994) such that there may be no difference in sex-chat experiences with ostensible human and machine partners.

Following, we broadly address the question of whether a sex-chat user and partner occupying the same ostensible category (human) is effectually different than when the user and partner are perceived to occupy different categories (human and machine, respectively). Findings indicate that there may be no difference in gratifications from chat with partners exhibiting signals of machine versus human categories; however, participants seem to experience tensions between gratifications and shortcomings of cybersex with machine-cued partners. These findings are interpreted through the lens of the Sexual Interaction Illusion Model (SIIM; Szczuka et al., 2019, published after the formulation of this study's design) to tentatively suggest that cued partner type may be less important than authenticity of the chat content and behaviors when it comes to experiencing enjoyment, arousal, and emotional gratifications.

\section{Review of Literature}

\section{Cybersex as Impactful Communication}

Current understandings of human-machine sexual communication springboard from knowledge surrounding the antecedents, processes, and effects of human-human sexual communication, so it is useful to ground this investigation first in that literature. Social platforms and mobile devices provide users with advanced opportunities for mediated textual and audiovisual sexual com munication (Van Ouytsel et al., 2018), fostering access to more potential partners and minimizing space and time restrictions than in offline spaces (Cockayne et al., 2017). Users may feel reduced inhibition to communicate about sexual topics because of the anonymity, asynchronicity, invisibility, and minimization of status and authority cues within online contexts (i.e., the online disinhibition effect; Suler, 2004), and the absence of some visual cues may make it easier to express sexual interest and wishes, especially those that are taboo in mainstream culture or that one would not actually perform (Carvalheira \& Gomes, 2003). Online sexual communication can take many forms, including webcam-based sexual activities, the sending of self-made sexually explicit pictures, and text-based sexual communication. In the present study, we focus on the latter.

Two main types of sexually explicit digital textual communication are sexting and cybersex; they share substantial conceptual overlap but are operationally distinct (Courtice \& Shaughnessy, 2017). Sexting is the exchange of sexually explicit text messages or pictures primarily through mobile texting applications (Van Ouytsel et al., 2018). Cybersex is "the interactive and realtime, internet-mediated exchange of sexually explicit messages" (Courtice \& Shaughnessy, 2017, p. 269). Cybersex within private or public chatrooms or messaging applications can take various forms that range from flirting, sexual discussion, and sharing fantasies to role-play with limitless sexual scenarios (Courtice \& Shaughnessy, 2017). Another difference between sexting and cybersex can be situated in the fact that with sexting, the users may already know each other on a personal level (e.g., within the context of dating or a romantic relationship) than with cybersex, which is more likely to occur on online platforms where users wish to remain anonymous (Döring, 2000; Van Ouytsel et al., 2018).

These mediated interactions are distinct from other sexual experiences in that direct physical interaction is absent (Carvalheira \& Gomes, 2003). There is a strong imaginary component associated with the potential for physical sensations. Because the entire sexual experience is text-based, participants must verbally describe sexual actions, sensations, and desires in ways uncommon in face-to-face sexual encounters (Döring, 2000). Nonverbal cues that would indicate a partner's arousal or satisfaction (e.g., facial expressions, sounds, and gestures) are absent and may be replaced by cues such as writing speed or emoticon use (Courtice \& Shaughnessy, 2017; Döring, 2000).

Cybersex can fulfill important needs regarding users' experiences of their sexuality. Due to potential anonymity, users may fulfill needs to honestly express feelings and to be more straightforward in sexual relationships (Carvalheira \& Gomes, 2003). It can free users from self-constraints, social control, and social and behavioral norms that are experienced in other relationships (Döring, 2000). Text-based sexual communication may allow users to break taboos and to experiment with identities by creating different personae, allowing experimentation with gender, age, and sexual preferences and identities (Courtice \& Shaughnessy, 2017). More broadly, cybersex use is motivated by desires to enhance sexual experience, escapism, and coping, realizing social interaction (Franc et al., 2018) and thrill or recreational arousal (Beyens \& Eggermont, 2014).

Nonetheless, the potential for cybersexual interactions to satisfy social, psychological, and physical needs appears to be especially important for individuals with lower social skills, removing barriers that are typically experienced in face-to-face relationships (Carvalheira \& Gomes, 2003). Users who have difficulties forming intimate relationships (e.g., because of fear of abandonment, rejection, or exposure) are more likely to seek out cybersex experiences in part due to potentially reduced performance anxieties (Weinstein et al., 2015). Perhaps most importantly, cybersex experiences provide users with safety and choice: unpleasant, intimidating, or nonconsensual interactions can be easily halted and the mediated quality of the interaction disallows physical dangers including sexually transmitted infections. This added safety may be liberating for those disproportionately at-risk for such dangers during physical sexual contact (Döring, 2000).

\section{Machines as Sexual Communication Partners}

Interactive media and machine-embodied agents have begun to challenge assumptions and norms about what can and should be a sexual partner. As social machines become more human-like in appearance, functioning, and/or behavior, the potential for humans and machines to cooperatively generate meaning through interaction (Guzman, 2018) may include sexual interactions. Although there is currently limited empirical evidence outside of humans' attitudes and speculations (e.g., Scheutz \& Arnold, 2017), it is hypothesized that the use of such machines as sexual partners could be a secure and low-risk alternative to human sexual contact (e.g., Appel et al., 2019). Similar to cybersex, these potentials may be especially important for individuals who are unable to engage in humanpartner relationships because of illness, recent loss of a partner, difficulties with sexual functioning, psychological issues, or disabilities (Coursey et al., 2019; Döring, 2017; Döring \& Pöschl, 
2018). The use of sex-purposed machines might increase sexual fulfillment and satisfaction, which, in turn, may lead to overall positive psychosocial outcomes (Döring \& Pöschl, 2018).

The dynamics of machines as social partners are nascently understood, largely through the lens of media equation theory: given sufficient social cues from a machine, we apply the same social norms and expectations to it (Reeves \& Nass, 1996) via mindless application of social heuristics and learned social behaviors (Nass \& Moon 2000). Limited empirical scholarship on sexual interactions between humans and machines has focused on embodied robots, differentiating between implicit and explicit elicitations of attraction to machines. Empirical evidence in this domain suggests that people exhibit differential gaze patterns when considering sexualized gynoid robots compared to humans: robotic bodies elicit greater visual exploration (likely a matter of novelty and curiosity) and human bodies elicit attention to face and chest areas (known markers of considered mate value; Szczuka \& Krämer, 2019), suggesting that humans and machines may be fundamentally approached as having different sexual values. Furthermore, men seem to express conflicting implicit and explicit attraction indicators: regarding sex-robot compared to human attractiveness, people rate humans as more attractive via explicit measures (self-reports), but there is no difference in implicit measures (Szczuka \& Krämer, 2017). Expressed likelihood of engaging in a sexual encounter with a robot is associated with greater sexual fantasizing and engaging in risky behaviors, as well as a lack of bias against robots, more generally (Richards et al., 2017). Extrapolating from studies in intimacy, generally, people may experience heightened physiological arousal in touching low-accessibility robot body parts (i.e., buttocks and groin, vs. pointing to high-accessibility parts) signaling a primitive, embodied response to touching a nonhuman body in intimate (though not necessarily sexual) ways (Li et al., 2017). Furthermore, the notion of one's partner engaging in sexual activity with a robot can evoke feelings of intimacy-related jealousy in the form of discomfort with a partner sharing emotional resources with a machine (Szczuka \& Krämer, 2018).

Despite emerging research attention to embodied sex robots, the actuality of and potential for humans engaging in sexual activities with machines goes far beyond humanoid hardware sex robots, especially because financial and market accessibility to such devices is limited. For more than a decade, sexual chatbots-mostly free and accessible on the web and social networks-have allowed users to engage in cybersex with chatbots (Döring, 2017). Chatbot use for the purposes of cybersex requires little technical skill, and a key driver for chatbot use is efficiency of access, bypassing the need for a real-life texting partner (Döring, 2017). Although text-based conversational agents-both text-only chatbots and graphically depicted personas-have been studied in detail (see Duijst, 2017 for a review), individuals' experiences with and gratifications from sexual human-machine communication are poorly understood (Szczuka et al., 2019).

\section{Exploring Ontological-Category Differences in Sexual Communication Partners}

The paucity of empirical scholarship in the HMC-S domain at this moment of rapid technological development and a growing market for chatbot-enabled cybersex points to a need to pause and evaluate fundamental dimensions of the experience of sexual chat with machine partners. As evidenced by the literature review on human-human cybersex interactions, HMC-S interactions may offer opportunities for psychosocial well-being and sexual exploration; however, it is yet unknown whether or not experiences and effects associated with machine partners will mirror those from human partners. Although the specific question of whether ontological-class cues may provoke differential experiences and gratifications from sex chat has not been addressed in extant scholarship, we may extrapolate from the literature that considers more general perceptions of and reactions to digital versus human agents.

The perception of agency is core to experiencing machine partners as social entities, as compared to human partners. The suggestion that a digital body is controlled by a human (i.e., an avatar vs. being technologically autonomous agent) elicits stronger social influence effects (Fox, Ahn, et al., 2015), promotes more prosocial behavior (Felnhofer et al., 2018), and engenders greater sadness at social exclusion (Kothgassner et al., 2017). Stronger perceived behavioral realism of an agent (independent of its actual autonomy) engenders more positive agent evaluations and feelings of mutual awareness (von der Pütten et al., 2010) such that there would seem to be clear differences in how people would experience HMC-S with human- and machine-cued partners. However, a parallel body of work indicates that there may be no meaningful difference in experiences or effects for ontological category of a sex-chat partner: trait sexism and objectification may manifest in relation to digital bodies (Nowak et al., 2015), and controlling a sexualized digital body contributes to self-objectification and indirectly influences rape myth acceptance (Fox, Ralston, et al., 2015). More broadly, humans have particular expectations for conversational agents in terms of machine intelligence, capabilities of systems, and goals for their use that are often not fulfilled by those agents (Luger \& Sellen, 2016), especially with respect to specific expectations for contingency-the variable alignment between a speaker's actions and a respondent's feedback, known to foster rapport with digital agents (Gratch et al., 2007).

Considering divergent responses to agents of different ontological categories, the key mechanism by which either may emerge is the interpretation of the category cues-those signals that prompt the activation of a specific category schema, including the agent's membership therein as well as the expectations for the agent's aims and behaviors (Gaudiello et al., 2015). This cueing is multimodal, comprising visual (e.g., expressions and gazes; cf. Chesher \& Andreallo, 2020), verbal (textual conveyances or vocalizations; Pradhan et al., 2019), and behavioral (e.g., social context awareness cues; Fraune et al., 2020) properties that denote a "living/nonliving," "born/made," and capability and agency distinctions (Guzman, 2020).

Although it may be tempting to apply to HMC-S what is currently understood about nonsexual HMC - for instance, the roles of social scripts (Edwards et al., 2019) and flattery (Fogg \& Nass, 1997)—it would be premature to do so. Specifically, it would rest on the assumption that known dynamics (principally, mindless reactions via the media equation) would extend to digital sexual interactions. Given inconsistent literature on the convergence and divergence of human experiences with human- and machine-cued interlocutors, this study takes as its aim an experimental comparison of some of the key dimensions in the evaluation of sexual communication and sexual media content (Oliveira et al., 2014; Youn, 2006): do people differ in their experiences of enjoyment of (RQ1), arousal from 
(RQ2), and affective response to (RQ3) sexual chat when they believe they are chatting with a human-cued partner compared to a machine-cued partner?

\section{Method}

To address these questions, an experiment was conducted in which participants (self-identified other-sex attracted individuals were recruited from online messaging boards related to sex chat, sexual intimacy, and sexual relationships) were asked to complete an anonymous online survey about "online sex-chat experiences" in exchange for entry into a drawing for a $\$ 150$ Amazon gift card (via a separate web form). Participants were asked to review consent information and study introduction in which they were told they would interact with a sex-chat partner, and were then prompted to choose the desired sex for their chat partner (male or female). They were then randomly assigned to either a "human" or "chatbot" partner of that sex (although, for experimental control, in both cases the partner was a chatbot). Of note, the type of partner was not mentioned until participants reached the chat screen to minimize $a$ priori assumptions that the partner could be a chatbot. Before encountering the partner, participants chose and entered an anonymous "special code" (any letter/number combination of at least six characters) to represent them in the survey. This code was entered at the beginning of the survey and on the chat interface page to link together the survey responses and chat transcripts, and then represented at the end with a reminder to take note of it in case they wished to rescind their data after the debriefing. After chatting, the survey solicited an open description of the experience and a manipulation check to verify correct perceptions of the gender (male/female) and the agent class (human/chatbot and a distractor option animal). Following, participants completed measures for enjoyment, arousal, and affective response. Finally, items to capture demographics and prior online chat experiences were presented. Participants were debriefed via email after data collection was complete, disclosing that the chat partner was always a chatbot and not a human; no participants elected to rescind their data. The procedures of this study were approved by the ethical committee of the second author's institution.

\section{Stimulus Chatbot and Chat Experience}

The chatbot, embedded within the survey interface, was one of four variations of a long-standing, publicly available sex chatbot that was customized for this study by the developer in cooperation with the researchers. The developer wished to remain anonymous and for the chatbot site go unnamed; however, complete chat transcripts (along with the survey, interface images, data files, and analysis outputs) are available via online supplements for this project: https:// osf.io/n9df7. Customization of the chatbot comprised the following: (a) visual and textual indicators for sex (male/female) and agent class (human/chatbot), (b) removal of chat responses dealing with sexual activities or outcomes illegal in the United States, and (c) lengthened typing-time lags such that it would be believable as a human partner.

Just before beginning the chat session, participants were primed with chat-partner sex and agent category via explicit identification of those features in the textual heading of the chat page, immediately above the chat window: "Your partner will be ... JAX, a [male/ female] [person/chatbot] and [he/she] is ready to chat." That textual prime was reinforced by the chat-partner avatars' aesthetic. Each static avatar image featured a neck-down stock photo of a scantily clad body (black bra and panties for the female, black underwear for the male) in a provocative pose, against a black background. For the human-cued condition, the image was photorealistic; for chatbot conditions, a Photoshop plastic-wrap filter was applied to the same images to engender a synthetic appearance (see supplements for stimulus images).

Participants were asked to spend at least 3 min chatting with the partner (reinforced by a survey page timer and validated by chat transcript). If participants encountered the chat interface but had not entered any text after a few seconds, the chatbot would begin with a benign but playful introduction (e.g., "Hey, what's happening?"); if the participant initiated the chat, the chatbot response would draw on its programming to produce a best-fit response.

\section{Measures}

Enjoyment was measured via the single relaxation, enjoyment, and humor items from the subjective sexual arousal scale (Kukkonen et al., 2010). Arousal was captured via the evaluative dimension of the Sexual Arousal and Desire Inventory (SADI; $\alpha=0.988$; Toledano \& Pfaus, 2006). Those measures were presented as 7-point scales assessing how much they experienced the descriptor, from not at all (1) to a whole lot (7). Arousal was additionally captured via items adapted from the subjective arousal scale ( $\alpha=0.964$; Kukkonen et al., 2010), presented as 5-point Likert-style scales assessing how well a statement described their arousal, from not at all (1) to perfectly (7). Affective response was captured via the SAM-PAD (Bradley \& Lang, 1994) featuring three single pictoral items: one each for pleasure, arousal, and dominance. Personological factors included the demographics captured via open-ended responses (subsequently coded for standardization): year of birth, sex assigned at birth, gender identity, and sexual orientation. The manipulation check was administered in two forms: (a) first an evaluation of an open-ended description of the experience for indicators of agent type followed by (b) a question "Which type of chat partner did you chat with?" with multiple-choice response options (female human, male human, female chatbot, male chatbot, and distractor items female animal and male animal) (see supplements for complete instrumentation).

\section{Data Processing}

Survey responses were matched to corresponding chat transcripts using the participant-generated anonymous code. Then, cases were verified for complete responses and valid chat transcripts. We removed those that did not enter a special code (disallowing survey/ transcript pairing, $n=268$ ), those that did not complete the chat encounter (i.e., clicked out of the survey before $3 \mathrm{~min}$ passed, $n=461)$. We removed one case missing the manipulation check, and cases where the key enjoyment, arousal, and affect metrics were not complete $(n=40)$. Finally, all chat transcripts were reviewed to ensure participants had completed an actual sex-chat experienced, operationalized as the participant having made at least one reference to a sexual activity (e.g., kissing, touching, or penetration) or concept (e.g., sexiness, desire, and arousal) in the course of actively 
contributing to the interaction. Cases were removed $(n=36)$ when one such reference was not made (see supplements for data file, variable "ChatValid"). This process resulted in $n=271$ usable cases.

\section{Results}

Participants were $M=31.90$ years old ( $S D=10.34), 80.5 \%$ male and $19.5 \%$ female sex assigned at birth (no intersex), and $91.8 \%$ straight. Cases reporting nonstraight identification were deemed acceptable for analysis as all identified as bisexual, curious, or pansexual such that the chatbot's language could still be appropriate. Chat sessions lasted $M=419 \mathrm{~s}(S D=314.79 \mathrm{~s}$, range 181.62-3144.47), or about $7 \mathrm{~min}$, and comprised $M=477.79$ words $(S D=368.49$, range 80-3919).

The content of chat sessions varied widely, and chatbot responses varied in relation to participant expressions. In terms of participant contributions, some included roleplay (e.g., "Fuck! Scream so the neighbors hear!" and "I let out a loud moan as I cum. You feel incredible"). Many offered general sexual encouragements ("Sure baby, I'll make u cum so hard"), while others asked permission ("do I have your consent") or made requests ("Be gentle with my throat"). Others gave statements of intent ("Yes I am going to fuck your ass" and "Mmmh ld love to stroke a thick load all over your lips"). Although most exchanges provoked involved responses, some rejected the partner (e.g., "I might as well be beating off dry") and others expressed doubt or otherwise pushed back on the intensity of the conversation ("That's... nice to hear. A little full on, isn't it?"). Complete transcripts are available in the supplementary material.

The manipulation check showed that although most people in the chatbot conditions passed the manipulation check (95.9\%), most in the human-cued condition did not believe they were talking to a human $(82.9 \%$ selected the option indicating their partner was a chatbot). At first blush this points to a failed manipulation. However, a review of participants' open-ended descriptions of the chat experience (completed before the categorical manipulation check) indicated that some failing the check still described the experience in ways aligned with their assigned condition. For instance, one participant assigned to a human female partner failed the check, but said he needed "some sort of information, background or kinks about the other person" and others offered more implicit forms of anthropomorphism such as gendered pronouns: "she didn't acknowledge what I was saying." This suggests that absent a prompt to identify the agent class, some people may have indeed experienced the chat according to the condition cues; this aligns with extant empirical work, suggesting that people heuristically process agent class (to positive or negative effect) unless they are prompted to elaborate on the behaviors or interactions (e.g., Lobato et al., 2013). Because the manipulation check cannot be said to be reliable or unreliable, a conservative analytical approach was used: the entire data set was analyzed, followed by reanalysis of only the participant subset that did pass the manipulation check (acknowledging low power in the latter).

Because nearly all dependent variables were correlated (many moderately or highly; Table 1), they were analyzed via a single MANCOVA comparing them across human-cued and chatbotcued conditions. In this analysis, comparisons controlled for chat word count (as a surrogate for how long participants were actively engaged in chat) and chat-partner sex $(0 / 1$ where $1=$ female because the sex-imbalanced sample prevented analysis along sexidentification lines). The multivariate model was not significant, indicating no difference in the dependent variables between those chatting with a partner primed as human compared to primed as chatbot: Pillai's trace $F(8,241)=0.505, p=.852$, partial $\eta^{2}=$ 0.016 (Box's $M=33.804, p=.630$ ). Neither word count nor chat partner sex contributed significantly to the model (Table 2). Notably, mean scores for enjoyment, arousal, and affect were all middling to high, suggesting participants did not generally dislike the chat experience.

As it was possible that nondifferences between conditions were a function of many people believing or speculating they were talking to a bot and not a human, the same tests were repeated for a subsample of participants: all 9 of 27 chatting with the male "human" and all 12 of 96 chatting with a female "human" partner who passed the manipulation check, plus parallel random subsamples of 9 and 12 individuals in the male chatbot and female chatbot who passed the check, respectively. There were, again, no significant differences by perceived chat partner type (controlling for word count and partner sex) for any of the dependent variables (Table 3). Although observed power is quite low (0.326, overall), we still interpret these results as supportive of nondifference between agent conditions as (a) effect sizes were quite low (multivariate partial $\eta^{2}=0.201$, univariate partial $\eta^{2}$ range $\left.=0.000-0.070\right)$ and $(b)$ the mean differences for all variables were less than 1-scale point $(M \Delta \leq 0.96)$. We tentatively and cautiously interpret this to suggest that - notwithstanding sex or length of discussion-there may be no significant differences between human- and bot-cued partners for enjoyment, arousal, or affective response to sexual chat.

Table 1

Correlations Among Enjoyment, Arousal, and Affect Measures

\begin{tabular}{|c|c|c|c|c|c|c|c|c|}
\hline & 1 & 2 & 3 & 4 & 5 & 6 & 7 & 8 \\
\hline 1. Relax & 1 & & & & & & & \\
\hline 2. Enjoy & $.424^{* * *}$ & 1 & & & & & & \\
\hline 3. Funny & $.154^{*}$ & $.171^{* *}$ & 1 & & & & & \\
\hline 4. Subjective & $.211^{* * *}$ & $.673^{* *}$ & -.075 & 1 & & & & \\
\hline 5. Evaluative & $.246^{* *}$ & $.736^{* *}$ & -.049 & $.896^{* *}$ & 1 & & & \\
\hline 6. Pleasure & $.379^{* *}$ & $.703^{* *}$ & .133 & $.598^{* *}$ & $.670^{* *}$ & 1 & & \\
\hline 7. Arousal & $.169^{* *}$ & $.644^{* *}$ & -.046 & $.758^{* *}$ & $.789^{* * *}$ & $.590^{* * *}$ & 1 & \\
\hline 8. Dominance & $.321^{* *}$ & $.197^{* *}$ & .047 & $.185^{* *}$ & $.163^{* *}$ & $.206^{* * *}$ & $.147^{*}$ & 1 \\
\hline
\end{tabular}

*Correlation significant at $p \leq .05$. ${ }^{* *}$ Correlation significant at $p \leq .01$. 
Table 2

For the Entire Data Set, Univariate Tests for Differences in Enjoyment, Arousal, and Affect Between Chatbot-Primed Partners Compared to Human-Primed Partners, Controlling for Chat Word Count and Partner Sex

\begin{tabular}{|c|c|c|c|c|c|c|c|}
\hline & $F(1,248)$ & $p$ & Partial $\eta^{2}$ & $\begin{array}{l}\text { Word count } p \\
\text { partial } \eta^{2}\end{array}$ & $\begin{array}{l}\text { Partner sex } p \\
\quad \text { partial } \eta^{2}\end{array}$ & $\begin{array}{c}\text { Human } M(S D) \\
n=107\end{array}$ & $\begin{array}{c}\text { Chatbot } M(S D) \\
n=145\end{array}$ \\
\hline \multicolumn{8}{|c|}{ Enjoyment (7-point scales) } \\
\hline Relax & 0.001 & .979 & 0.000 & $.08,0.013$ & $.09,0.011$ & $4.60(1.94)$ & $4.59(1.78)$ \\
\hline Enjoy & 0.060 & .807 & 0.000 & $.01,0.026$ & $.13,0.009$ & $3.36(1.80)$ & $3.43(1.77)$ \\
\hline Funny & 0.028 & .868 & 0.000 & $.23,0.006$ & $.67,0.001$ & $4.19(2.00)$ & $4.16(1.85)$ \\
\hline \multicolumn{8}{|c|}{ Arousal (7-point scales) } \\
\hline Subjective & 0.080 & .778 & 0.000 & $.02,0.023$ & $.38,0.003$ & $3.18(1.77)$ & $3.18(1.87)$ \\
\hline Evaluative & 0.290 & .591 & 0.001 & $.02,0.020$ & $.85,0.000$ & $3.03(1.66)$ & $2.95(1.68)$ \\
\hline \multicolumn{8}{|c|}{ Affect (5-point scales) } \\
\hline Pleasure & 0.872 & .351 & 0.004 & $.01,0.025$ & $.17,0.008$ & $3.13(1.12)$ & $3.26(1.01)$ \\
\hline Arousal & 0.009 & .924 & 0.000 & $.07,0.013$ & $.31,0.004$ & $2.49(1.22)$ & $2.48(1.22)$ \\
\hline Dominance & 0.020 & .888 & 0.000 & $.14,0.009$ & $.50,0.002$ & $2.76(1.50)$ & $2.74(1.51)$ \\
\hline
\end{tabular}

\section{Post Hoc Thematic Analysis of Experience Descriptions}

As a first step in validating or discounting the tentative interpretations of the primary statistical analysis and to offer directions for future research in this domain, interpretive thematic analysis was conducted to extract patterns in subjective experience in five steps: deep reading of responses, open coding of data features, code unification, theme reduction, articulation of theme prevalence and relevance, and cross-referencing with relevant literatures (per Braun \& Clarke, 2006). The analysis was conducted by the first author (with expertise in human-machine communication) and the results were reviewed for face validity by the second author (with expertise in sexual communication). Although frequency counts are presented here, they are intended only as signals of each theme/category's prevalence within the data because the aim of the exploratory interpretive analysis is to highlight the complexities of the experience and consider any qualitative patterns that could support, shift, or disconfirm our interpretation of the primary analysis. Although only higher level theme hierarchies and exemplars are presented here, documentation of the interpretive analysis processes is available in this project's supplementary materials.

Codes were assigned to data units (here, units were discrete, complete sentiments). Coding resulted in 103 unique codes assigned to 1071 data units across the 264 cases that included an open description. Codes were iteratively reduced to eight experiential themes comprising 23 code categories. Themes extracted, by prevalence, are in Table 4 (see supplements for complete analysis narrative and coded data).

1. Effects included chatters' felt affective or physiological/ behavioral reactions (both positive and negative) to the chat experience, trending toward more negative affective responses and more positive physical/behavioral responses-these effects were often not exclusive, which may have engendered stress responses (Russell et al., 1989).

2. Experiences characterized by (Dis)Order highlighted the randomness, nonlinearity, decontextualization, or disjointedness of the conversation (largely due to the bot's keyword-based rather than semantic responses) and/or the feeling that the content was too ordered (systematic, scripted, or repetitive). This lack of conversational contingency (semantic reference to preceding responses; Sundar et al., 2016) and interactional coherence (turn-taking logical in content and sequence; Herring, 1999) have been linked to lower interaction satisfaction in other chat contexts (Lew et al., 2018).

Table 3

For the Subsample Passing the Manipulation Check, Univariate Tests for Differences in Enjoyment, Arousal, and Affect Among Between Chatbot-Primed Partners Compared to Human-Primed Partners, Controlling for Chat Word Count and Partner Sex

\begin{tabular}{|c|c|c|c|c|c|c|c|}
\hline & $F(1,35)$ & $p$ & Partial $\eta^{2}$ & $\begin{array}{l}\text { Word count } p, \\
\text { partial } \eta^{2}\end{array}$ & $\begin{array}{l}\text { Partner sex } p, \\
\text { partial } \eta^{2}\end{array}$ & $\begin{array}{c}\text { Human } M(S D) \\
n=18\end{array}$ & $\begin{array}{c}\text { Chatbot } M(S D) \\
n=21\end{array}$ \\
\hline \multicolumn{8}{|c|}{ Enjoyment (7-point scales) } \\
\hline Relax & 0.000 & .993 & 0.000 & $.52,0.012$ & $.32,0.029$ & $4.44(2.18)$ & $4.29(1.85)$ \\
\hline Enjoy & 0.114 & .738 & 0.003 & $.83,0.001$ & $.48,0.014$ & $3.89(2.19)$ & $3.67(1.71)$ \\
\hline Funny & 0.852 & .362 & 0.024 & $.56,0.010$ & $.27,0.035$ & $3.17(2.12)$ & $3.86(2.03)$ \\
\hline \multicolumn{8}{|c|}{ Arousal (7-point scales) } \\
\hline Subjective & 2.156 & .151 & 0.058 & $.46,0.016$ & $.80,0.002$ & $3.97(2.00)$ & $3.13(1.95)$ \\
\hline Evaluative & 2.514 & .113 & 0.070 & $.74,0.003$ & $.66,0.006$ & $3.90(1.81)$ & $2.94(1.74)$ \\
\hline \multicolumn{8}{|c|}{ Affect (5-point scales) } \\
\hline Pleasure & 2.416 & .129 & 0.065 & $.45,0.017$ & $.17,0.052$ & $3.61(1.34)$ & $3.05(1.02)$ \\
\hline Arousal & 2.514 & .122 & 0.067 & $.34,0.027$ & $.76,0.003$ & $3.11(1.37)$ & $2.48(1.40)$ \\
\hline Dominance & 0.536 & .469 & 0.015 & $.87,0.001$ & $.46,0.015$ & $2.83(1.47)$ & $2.48(1.44)$ \\
\hline
\end{tabular}


Table 4

Thematic Hierarchy Detailing Chatters' Critiques of Sex-Chat Experiences

\begin{tabular}{|c|c|c|c|}
\hline $\begin{array}{l}\text { Theme } \\
\text { ( } n \text { instances) }\end{array}$ & Category & Subcategories (codes) & Exemplars \\
\hline \multirow[t]{2}{*}{ Effects (229) } & $\begin{array}{l}\text { Affective Response (positive } \\
\text { [55]/negative [77]) }\end{array}$ & $\begin{array}{l}\text { Negative response (intimidation, unnatural } \\
\text { feeling, weird, annoying, discomfort, } \\
\text { disorientation, awkward, overwhelming, } \\
\text { infidelity); positive (enjoyment, fun, } \\
\text { entertainment, exciting, humorous, surprise, } \\
\text { liberating, desiring the real, intimacy) }\end{array}$ & $\begin{array}{l}\text { "It was a bit awkward, honestly." [negative/ } \\
\text { awkward] } \\
\text { "The experience was nice." [general positive] }\end{array}$ \\
\hline & $\begin{array}{l}\text { Physiological/Behavioral } \\
\text { Response (positive [63]/ } \\
\text { negative [34]) }\end{array}$ & $\begin{array}{l}\text { Positive response (aroused, acting on arousal); } \\
\text { negative response (unaroused, terminating } \\
\text { interaction) }\end{array}$ & $\begin{array}{l}\text { "The chat was so hot and made me want it for } \\
\text { real." [arousal] } \\
\text { " . . the specific things they said didn't really } \\
\text { turn me on." [unaroused] }\end{array}$ \\
\hline \multirow[t]{2}{*}{ (Dis) Order (167) } & Disjointed (100) & $\begin{array}{l}\text { Disjointed, inconsistent, no flow, random, out } \\
\text { of context }\end{array}$ & $\begin{array}{l}\text { "It also jumped too much. Sometimes the } \\
\text { exchanges was sweet and romantic, other } \\
\text { times it was explicit and raunchy." } \\
\text { [disjointed + inconsistent] }\end{array}$ \\
\hline & Automaticity (67) & $\begin{array}{l}\text { Automatic, scripted, keyword-driven, limited } \\
\text { capacity, repetitive }\end{array}$ & $\begin{array}{l}\text { "I could tell it was an automatic preset system." } \\
\text { [automatic] } \\
\text { "I became aware of the way it picks up certain } \\
\text { keywords and responds." [keywords] }\end{array}$ \\
\hline \multirow[t]{4}{*}{$\begin{array}{l}\text { (In)Authenticity } \\
\text { (144) }\end{array}$} & (Un)Realism (69) & Un/realistic, fake & $\begin{array}{l}\text { “... it was super fake ..." [fake] } \\
\text {... most of the time I felt like I was actually } \\
\text { sexting someone." [realism] }\end{array}$ \\
\hline & Presence (19) & Immersion, visualization, descriptiveness & $\begin{array}{l}\text { "The bot did a great job at providing plenty of } \\
\text { visual encouragement." [description] } \\
\text { "I kinda kept up with the fantasies of the bot." } \\
\text { [immersion/fantasy] }\end{array}$ \\
\hline & (In)Humanity (28) & $\begin{array}{l}\text { Artificiality, objectification, persona } \\
\text { evaluations }\end{array}$ & $\begin{array}{l}\text { "No human aspect or connection." [inhuman] } \\
\text { "... it was more like she was having sex AT me } \\
\text { than WITH me." [objectification] }\end{array}$ \\
\hline & Formal Features (28) & $\begin{array}{l}\text { Grammar, vocabulary, response length, } \\
\text { roleplay, narrative }\end{array}$ & $\begin{array}{l}\text { “... the vocabulary is on point." [vocabulary] } \\
\text { ".. some of the messages were too long." } \\
\text { [length] }\end{array}$ \\
\hline \multirow[t]{2}{*}{$\begin{array}{l}\text { (Non)Interactivity } \\
\quad(124)\end{array}$} & Responsiveness (79) & Non/responsive, non/reciprocal, non/interactive & $\begin{array}{l}\text { "Not really responding much to what I was } \\
\text { saying, just throwing out random stories." } \\
\text { [nonresponsive] } \\
\text { ". . not very interactive, like reading a book." } \\
\text { [noninteractive] }\end{array}$ \\
\hline & $\begin{array}{l}\text { Lack of Agency/Influence } \\
\text { (45) }\end{array}$ & $\begin{array}{l}\text { Control (or lack of), forced, impersonal, } \\
\text { godmoding }\end{array}$ & $\begin{array}{l}\text { "I love talking dirty over text because I can } \\
\text { make it as sensual or as dirty as I want." [high } \\
\text { control] } \\
\text { "Jax was just saying whatever she was scripted } \\
\text { to say and my inputs didn't really mean } \\
\text { anything." [low control] }\end{array}$ \\
\hline \multirow[t]{3}{*}{$\begin{array}{l}\text { Agent Class } \\
\text { Salience (122) }\end{array}$} & Class Identification (87) & Identification (rote), identification (evaluative) & $\begin{array}{l}\text { "obviously a chatbot." [rote] } \\
\text { "that bot was awful." [evaluative] }\end{array}$ \\
\hline & Class Rejection (22) & $\begin{array}{l}\text { Class rejection, class uncertainty, class } \\
\text { suspicion, class comparison }\end{array}$ & $\begin{array}{l}\text { "... it was easy to figure out it was a bot and not } \\
\text { a human." [rejection] } \\
\text { "I'm certain that they were either a research } \\
\text { student using a penthouse letters PDF or bot." } \\
\text { [suspicion] }\end{array}$ \\
\hline & $\begin{array}{l}\text { Class Knowledge Influence } \\
\text { (13) }\end{array}$ & Class knowledge effect & $\begin{array}{l}\text { "Knowing your chatting with a bit removes the } \\
\text { sexual charge for me." [effect] }\end{array}$ \\
\hline
\end{tabular}


Table 4 (continued)

\begin{tabular}{|c|c|c|c|}
\hline $\begin{array}{l}\text { Theme } \\
\text { ( } n \text { instances) }\end{array}$ & Category & Subcategories (codes) & Exemplars \\
\hline \multirow[t]{4}{*}{$\begin{array}{l}\text { Personological } \\
\text { Factors (99) }\end{array}$} & (In)Experience (23) & Skill, experience, difficulties & $\begin{array}{l}\text { "I've been sexting for over } 20 \text { years ..." } \\
\text { [experience] } \\
\text { ". . . found it somewhat difficult to find the right } \\
\text { words or mental space." [difficulty] }\end{array}$ \\
\hline & Preference (15) & Comparison against preferences, appetite & $\begin{array}{l}\text { "I'd prefer to get to know someone before we } \\
\text { started doing things." [preference] }\end{array}$ \\
\hline & Approach to Chat (18) & $\begin{array}{l}\text { Suspension of disbelief, engage fantasy, limited } \\
\text { response, realistic, experimentation }\end{array}$ & $\begin{array}{l}\text { "I did try to respond to the bot how I would to a } \\
\text { real sexting partner ..." [realistic] } \\
\text { "I started to have fun and just say things to see } \\
\text { what the reaction was." [experimentation] }\end{array}$ \\
\hline & Valuation (43) & Ridiculous, pointless, novel, expectations & $\begin{array}{l}\text { "It was the stupidest thing I've ever done." } \\
\text { [ridiculous] } \\
\text { "It was interesting to see my own reactions to } \\
\text { sex talk." [novel] }\end{array}$ \\
\hline \multirow[t]{3}{*}{ Prurience (96) } & Extreme $(21)$ & Excessive, extreme, explicit, inappropriate & $\begin{array}{l}\text { "The bot was way over the top. She had all the } \\
\text { subtlety of a toddler in a candy shop." } \\
\text { [excessive] } \\
\text { ". . a little full on and vulgar too quickly." } \\
\text { [explicit] }\end{array}$ \\
\hline & Aggressive (54) & Aggressive, fast to sex, blunt & $\begin{array}{l}\text { "She just went at it when I said what's up." } \\
\text { [aggressive] } \\
\text { "Lacked some finesse." [blunt] }\end{array}$ \\
\hline & Prototypical (21) & Genre/porn, kinks & $\begin{array}{l}\text { "I felt I was thrown into a porn script." [genre] } \\
\text { "just jumped into a dom and sub situa- } \\
\text { tion." [kink] }\end{array}$ \\
\hline \multirow[t]{3}{*}{ Pacing (83) } & Needs Buildup (36) & Needs buildup, was no buildup & $\begin{array}{l}\text { "There was no teasing, no working up to it." [no } \\
\text { buildup] } \\
\text { "... part of sexy chatting is building up to the } \\
\text { hardcore ..." [needs buildup] }\end{array}$ \\
\hline & Escalation (21) & Escalation speed & "It went from 0 to 100 very quick" [escalation] \\
\hline & Pace (26) & Conversation pace, response speed & $\begin{array}{l}\text { "The instant response didn't allow for mush } \\
\text { time to process everything." [response speed] } \\
\text { "It was a bit rushed." [pace] }\end{array}$ \\
\hline
\end{tabular}

3. Participants evaluated the (In)Authenticity of the conversation, relative to either a human standard or a sex chatquality standard. They critiqued the experience as varied in social realism, as variably facilitative of immersion, as variable in offering human(-like) connectedness, and critiqued the formal features of the chat (most often that text was too lengthy or that metaphors like "kielbasa" would never normally be used) such that these critiques could be conceived of as social realism, or trueness-to-life (Lombard \& Ditton 1997) save for their focus on chatters' ideals for sexual chat interactions.

4. Many mentioned (Non)Interactivity, whereby chatters largely felt the partner was not appropriately responsive or not considering the participant's sexual interests or needs. Independently or in tandem, some chatters felt that they had no control over the conversation, while others felt the partner was patient and considerate. Personalized, tailored responses are thought to be key to chat-interaction satisfaction, especially if chatters perceived the interaction to be a form of service encounter (Verhagen et al., 2014).

5. The Agent class of the partner was salient to a number of chatters such that some merely identified the class, some rejected or were suspicious of the primed class, and others suggested that knowing the class influenced their experience of the chat. Tendencies to categorize agents into prototypical groups occur early in life (see Kahn et al., 2011).

6. Personological factors included acknowledgements of chatters' skills or experience, preferences, strategic approaches to chat, or personal (de)valuations of the experience as worthwhile or ridiculous. Salience of self or reflexivity could signal activation of enhancement gratifications (internal positive reinforcement associated with cybersex; Franc et al., 2018).

7. Those concerned with the chat's Prurience largely critiqued its aggressiveness, explicitness, or pornographic 
character. Critiques of sexual content may be linked to the chatbot's quick escalation (see pacing below) but was more generally termed "over the top."

8. Some chatters critiqued the Pacing as too quick to escalate to hardcore content or more specifically as needing buildup to that content, or that the chat moved too quickly overall (sometimes leading to guilt because chatters could not respond reciprocally). Broadly, the chat speed seems to have deviated from normative sexual scripts (see Simon \& Gagnon, 1986).

These themes and categories were often co-occurring, suggesting a number of tensioned sentiments. First, participants seemed to desire human(-like) sexual chat experiences and gratifying effects despite their awareness of agent class, such that chatters' dissatisfaction with the experience can be attributed to cognitive dissonance in terms of wanting the machine to be less machinic in the course of engaging in a traditionally human activity. For instance, a male participant noted: "She said some hot things but I wish we would have some continuity." In the broadest sense, this seems to manifest as a desire for personalization, attention, reciprocity, responsiveness, and a feeling of personally mattering in the conversation through realized agency and influence on the content and flow. A male participant exclaimed "I have the dick can't I have a say in the way we chat?" and another opined that it "wasn't what the connection between 'people' was suppose to be." That is, overall, participant responses suggest a wish to feel like a legitimate participant in the activity and to feel as though the partner was likewise a legitimate participant. That desire seems to be irrespective of what kind of partner was engaged.

Co-occurring themes also revealed a tension between salient, postexperience critiques of the chat and the experienced gratifications: participants were critical of the fashion by which the chat unfolded, but still enjoyed the experience as a social or sexual exchange. For instance, one chatter said "that felt impersonal, but still arousing" and another elaborated "the chatbot thing was again a little bit unnatural and faster and crowded of words. Anyways it still created some sexual tension and imagination even arousal." Another female participant who did pass the manipulation check was still put off by the mechanics of the chat but was gratified, saying "obvious he wasn't paying attention to what I was saying, but I still managed to cum."

Finally, primed agent class seemed to be an anchor for evaluating the experience. If chatters were told their partner was human, they seemed to hold high expectations for the interaction and were critical, disappointed, or angry when it did not meet expectations: "... it was too obvious it was not a real female. It was like I just wanted to ejaculate quickly then leave." When told they were chatting with a chatbot, responses often suggested that it met expectations (even if those expectations were low) or exceeded expectations: "Not entirely how an interaction with a real woman would be but ... I was pleasantly surprised by it ..." and another said "it was clear very soon this was a bot. Still, the bot had some pretty good, contextual responses."

\section{Discussion}

This study investigated people's experienced gratifications from cybersex chat with human- and chatbot-cued partners, finding no statistical difference in self-reported levels of enjoyment, arousal, and affective response to the experience. As such, there cannot be said to be an effect of ontological-category cueing on participant's gratifications from non/human-cued sex chat partners. Post hoc interpretive analysis of these individuals' descriptions of the experience indicate varied evaluations of content (in/authenticity, agent class salience, and prurience), structure (dis/order, non/interactivity, and pacing), antecedents (personological factors), and effects (both affective and physical). These evaluations often co-occurred in tension. We tentatively interpret these findings, together, to suggest that gratifications may be realized from textual cybersex irrespective of the cued agent type; however, dissatisfaction may emerge when the experience does not conform to normative or preferred sexual scripts for the form and content of the interaction.

\section{Theoretical Implications}

We interpret these findings cautiously, given the tentativeness of the manipulation check and that a lack of significant difference does not necessarily confirm nondifference. Broadly, the present findings echo extant research related to nonsexual communication finding that effects of talking about feelings (e.g., feeling better, partner warmth, or enjoyment of the interaction) are the same whether respondents believe they are engaging in emotional self-disclosure with a person or with a chatbot (Ho et al., 2018) and that more general perceptions of interacting with avatars or humans are indistinct (von der Pütten et al., 2010). This interpretation aligns with the perspective that computers are social actors in which cued ontological class is irrelevant in interactions so long as the agent and situation engage appropriate messages and social scripts, such that social responses have relative parity (Nass et al., 1994). However, evidence also supports threshold models of social influence in which the sociality of an agent is verified through perceptions of the agent having met behavioral realism and agentic capacity benchmarks (Blascovich, 2002; cf. von der Pütten et al., 2010). Specifically, post hoc interpretive analysis suggests that chatters sought realism and continuity across primed agent types and desiring social, narrative, and technical authenticity and continuity in their experience, even when told or inferring that their partner was a chatbot rather than a human. These findings are best interpreted by contextualizing them in a nascent theoretical framework: the SIIM (Szczuka et al., 2019), where the illusion is the automatic sensation of sexual experience with a machine knowing that sensation is not actually occurring, characterized by the suppression of certainty regarding the nonhumanness of the partner resulting in feeling that a sexual interaction is phenomenologically equivalent to that with a human. The present analysis provides support for most of the SIIM's components and pathways.

According to SIIM, the extent to which a sexual experience with a machine may lead to sexual arousal is influenced by "goodness-ofartificial-fit" (Szczuka et al., 2019, p. 11). The authors hypothesize that the quality of this fit is influenced by (a) the machine's displayed sexual behavior (i.e., its conformation to preferred or normative sexual scripts) and (b) the extent to which the machine's displayed features dis/conform to the kind of agent perceived to be a fit partner (e.g., its human-likeness, gender, and body shape).

Post hoc analysis suggests that participants experienced variable goodness-of-artificial-fit for both of these factors. For some there was a misfit of script, as some participants felt the chatbot violated 
preferred human or agnostic sexual scripts for cybersex interactions by way of structural qualities (e.g., grammar, response length, and pacing) or lack of personalization (e.g., diminished interactivity or nonadherence to preferences). As interactivity and reciprocity have been found to be important characteristics of human-machine communication in prior research (Sandoval et al., 2016), the structural qualities of a sexual chat may be especially important: users rely solely on the quality of textual conversation to stimulate their sexual fantasies in the absence of physical body cues present during other types of sexual interaction (Döring, 2000). For others there was a misfit of interaction partner features, as evidenced by the expressed direct or indirect influence of agent-class salience on the experience. Interpreted from a SIIM frame, each of these fit factors influences the perception of sexual explicitness that variably influences sexual arousal. In the present analysis, participants expressed positive or negative evaluations of the cybersex's prurient natureto some it was too hardcore, for some too take, and for some just to their liking; these were often linked (as theorized in the model) to the most frequently appearing theme of varied affective or physical effects (including sexual arousal) ranging from disdain and nonarousal to delight and complete sexual gratification.

The other component of SIIM considers the positive or negative influence of artificiality on the sexual interaction illusion via sensations of artificiality (i.e., machinic cues) and sensations of naturalness (e.g., interactivity, communication, and social role fulfillment); the illusion is theorized to directly influence sexual arousal. Indeed, the themes around sensed artificiality and naturalness (agent class salience, in/authenticity, and non/interactivity) were often in tension with both affective and physical responses to the cybersex experience. Notably, despite means suggesting neutral to low gratifications from the chat experience across both conditions such that it may be tempting to consider the dynamics as negatively valenced, some participants engaged the experience to positive effect. Some reported the experience to be interactive, authentic, appropriately ordered and paced, ideal in content, and/or even heightened by the knowledge that the partner was a chatbot. According to Szczuka et al. (2019), personal attitudes, preferences, and propensities likely influence the sex-chat partner's goodness-of-fit parameters.

Altogether, in the present investigation the low means for selfreported arousal across the board may be interpreted in tandem with the induced themes to be in support of SIIM: scripts and agent-type salience along with senses of competing artificiality and naturalness seem to be variably associated with both the illusion of an actual sexual encounter and sexual arousal. Just as sexual involvement, arousal, and gratification are understood to emerge in relation to such human interaction factors as fit between the immediate interaction and sexual interaction scripts (Mosher, 1988) and partner reciprocity (Muehlenard \& Shippee, 2010), so too may those emerge in HMC-S. In other words, it may be that the ontological class of the partner matters less than the sex-chat content and structure adherence to the norms and preferences for a fit partner. Without that perceived fit, the illusion is lost to conspicuous artificiality (Szczuka et al., 2019).

\section{Limitations and Implications for Future Research and Practice}

The present study is subject to a number of limitations that should be kept in mind when interpreting the results. First, the convenience sample was narrow and imbalanced: predominantly male (perhaps a self-selection bias), straight (as a pragmatic constraint given the language of the customized but preexisting chatbot), and recruited from anonymous messaging boards that focused on sex-chat or relationship topics (as a means of eliciting responses from those already participating in sex-chat activities). The respondents who self-selected may have had above-average sex-positive attitudes or prior experiences with cybersex, as some even described cybersex as a craft or a pastime. Future studies should rely on alternative sampling techniques to explore the extent to which these findings may (not) generalize to female-identifying, non-neterosexual, inexperienced, and/or attitudinally distinct populations.

Furthermore, the validity of the manipulation is uncertain, as many respondents in the human condition failed to pass our manipulation check, and potential failures result in low power for our analyses. We selected and customized an existing, free, publicly available sex-chat bot that. Although this enhanced ecological validity and potential generalizability and because the stimulus was evaluated by testers to the most believable among such options, the selection also inherently carried the limitations of the state of the technology itself. This necessarily impacted the results as evidenced by the strong critiques of the experience. Future studies should adopt alternative chatbots (especially as the technology advances through machine learning) or adopt a different methodological approach, by, for instance, using a "Wizard of $\mathrm{Oz}$ " technique as has been used in other research on chatbots (Ho et al., 2018), and may consider the wider range of possible sexual scripts that excluded in this investigation as a matter of illegality (i.e., rape, bestiality) but may nonetheless be pertinent to chat's potential to satisfy sexual fantasies.

Despite these limitations, findings reveal some important avenues for future research. As we began with a limited set of variables to compare, future research could take into account personality variables that might affect a sexual chatbot experience because sexual attraction and technology affinities are both thought to have personality correlates (Barnett et al., 2015; Lorenzo et al., 2010). A potential covariate for future research may be to account for individuals' attitudes, such as the openness to sexual experiences in tandem with preexisting attitudes toward machine agents. Szczuka et al. (2019) theorize that being reminded of the normative inappropriateness of the sexual interaction and the violation of social norms might negatively affect the experience for those with more conservative sexual attitudes, which warrants also considering moral valuations in future work. Other interesting covariates suggested by SIIM might be the flow (or synchronic entrainment as "sexual trance"; see Safron, 2016, p. 4) experienced during the sexual chat, as users who are more immersed in the experience might also be more likely to ignore negative cues that remind them of the artificiality of the interaction, consequently improving their chatbot experience. In tandem, it is possible that-although some chat content supports the problematic reception of hardcore and fastpaced content-participants' explanations of their chat experiences are more rational sense-making outputs that may or may not alignment with the actual experience. For instance, the request to explicitly describe the experience may have resulted in overly critical accounts from individuals who nonetheless engaged in suspension of disbelief (willing engagement of the fantasy) during the chat itself. Future research should explore potential dis/alignments between direct and indirect indicators of engagement, for 
instance, through the triangulation of psychophysiological metrics and self-reports. In addition, it is prudent to consider these dynamics in relation to other machine-facilitated sexual interactions, such as the use of "kissengers" or other devices that facilitate non-copresent sexual interactions (Hauskeller, 2014).

Our study also offers some practical implications for developers of cybersex chatbots. Most notably and positive for developers is that the sexual gratifications derived from cybersex may very well be independent of whether someone believes that they are communicating with a human or artificial partner. Rather than conceal a bot's status, it may actually benefit the chat experience to disclose its ontological class because participant suggested greater propensity to forgive a bot's script deviations, but to more harshly judge human deviations. Most broadly, in order to achieve a satisfying experience the cybersex chat must adhere to normative or preferred human sexual scripts in order to maintain the illusion of an actual sexual experience-principally scripts associated with the structure (flow, realism, reciprocity, and pacing) and content (realism, personalization, and explicitness) of the exchange.

\section{Conclusion}

Toward unpacking the black-box phenomenon of sexual humanmachine communication, this exploratory work yielded a paradox: despite possible parity in (non-)gratification from sex chat with human and machine partners, (dis)satisfaction with the content and structure of the chat existed in tension with potential and realized gratifications. As people engaged in HMC-S sought meaning, continuity, and believability in their experiences, fostering gratifying cybersex (toward healthy, safe, and inclusive sex alternatives) may rely less on concealing the artificiality of the agent and more on concealing the artificiality of the message.

\section{References}

Appel, M., Marker, C., \& Mara, M. (2019). Otakuism and the appeal of sex robots. Frontiers in Psychology, 10, Article 569. https://doi.org/10.3389/ fpsyg.2019.00569

Barnett, T., Pearson, A. W., Pearson, R., \& Kellermanns, F. W. (2015). Fivefactor model personality traits as predictor of perceived and actual usage of technology. European Journal of Information Systems, 24(4), 374-390. https://doi.org/10.1057/ejis.2014.10

Banks, J., \& Van Ouytsel, J. (2020, June 9). Cybersex with human- and machine-cued partners: gratifications, shortcomings, and tensions. https:// doi.org/10.17605/OSF.IO/N9DF7

Beyens, I., \& Eggermont, S. (2014). Prevalence and predictors of text-based and visually explicit cybersex among adolescents. Young, 22(1), 43-65. https://doi.org/10.1177/0973258613512923

Blascovich, J. (2002). A theoretical model of social influence for increasing the utility of collaborative virtual environments. In Proceedings of the 4th international conference on collaborative virtual environments (pp. 25-30). ACM. https://doi.org/10.1145/571878.571883

Bradley, M. M., \& Lang, P. J. (1994). Measuring emotion: The selfassessment manikin and the semantic differential. Journal of Behavior Therapy and Experimental Psychiatry, 25(1), 49-59. https://doi.org/ 10.1016/0005-7916(94)90063-9

Braun, V., \& Clarke, V. (2006). Using thematic analysis in psychology. Qualitative Research in Psychology, 3(2), 77-101. https://doi.org/10.1191/ 1478088706qp063oa
Carvalheira, A., \& Gomes, F. A. (2003). Cybersex in Portuguese chatrooms: A study of sexual behaviors related to online sex. Journal of Sex \& Marital Therapy, 29(5), 345-360. https://doi.org/10.1080/00926230390224729

Chesher, C., \& Andreallo, F. (2020). Robotic faciality: The philosophy, science and art of robot faces. International Journal of Social Robotics. Advance online publication. https://doi.org/10.1007/s12369-020-00623-2

Cockayne, D., Leszczynski, A., \& Zook, M. (2017). \#HotForBots: Sex, the non-human and digitally mediated spaces of intimate encounter. Environment and Planning D: Society and Space, 35, 1115-1133. https://doi.org/ 10.1177/0263775817709018

Coursey, K., Pirzchalski, S., McMullen, M., Lindroth, G., \& Furuushi, Y. (2019). Living with Harmony: A personal companion system by Realbotix. In Y. Zhou \& M. H. Fischer (Eds.), AI love you: developments in human-robot intimate relationships (pp. 77-95). Springer International. https://doi.org/10.1007/978-3-030-19734-6_4

Courtice, E. L., \& Shaughnessy, K. (2017). Technology-mediated sexual interaction and relationships: A systematic review of the literature. Sexual and Relationship Therapy, 32(3-4), 269-290. https://doi.org/10.1080/ 14681994.2017.1397948

Cox-George, C., \& Bewley, S. (2018). I, sex robot: The health implications of the sex robot industry. BMJ Sexual \& Reproductive Health, 44(3), 161-164. https://doi.org/10.1136/bmjsrh-2017-200012

Döring, N. (2000). Feminist views of cybersex: Victimization, liberation, and empowerment. CyberPsychology \& Behavior, 3(5), 863-884. https:// doi.org/10.1089/10949310050191845

Döring, N. (2017). Vom Internetsex zum Robotersex: Forschungsstand und Herausforderungen für die Sexualwissenschaft. Zeitschrift für Sexualforschung, 30(01), 35-57. https://doi.org/10.1055/s-0043-101471

Döring, N., \& Pöschl, S. (2018). Sex toys, sex dolls, sex robots: Our under-researched bed-fellows. Sexologies: European Journal of Sexology and Sexual Health, 27(3), e51-e55. https://doi.org/10.1016/j.sexol.2018 .05 .009

Duijst, D. (2017). Can we improve the user experience of chatbots with personalisation? [Unpublished master's thesis]. University of Amsterdam.

Edwards, A., Edwards, C., Westerman, D., \& Spence, P. R. (2019). Initial expectations, interactions, and beyond with social robots. Computers in Human Behavior, 90, 308-314. https://doi.org/10.1016/j.chb.2018.08.042

Eskins, R. (2017). Is sex with robots rape? Journal of Practical Ethics, 5(2), $62-76$.

Felnhofer, A., Kafka, J. X., Hlavacs, H., Beutl, L., Kryspin-Exner, I., \& Kothgassner, O. D. (2018). Meeting others virtually in a day-to-day setting: Investigating social avoidance and prosocial behavior towards avatars and agents. Computers in Human Behavior, 80, 399-406. https:// doi.org/10.1016/j.chb.2017.11.031

Fogg, B. J., \& Nass, C. (1997). Silicon sycophants: The effects of computers that flatter. International Journal of Human-Computer Studies, 46(5), 551-561. https://doi.org/10.1006/ijhc.1996.0104

Fox, J., Ahn, S. J., Janssen, J. H., Yeykelis, L., Segovia, K. Y., \& Bailenson, J. N. (2015). Avatars versus agents: A meta-analysis quantifying the effect of agency on social influence. Human-Computer Interaction, 30(5), 401-432. https://doi.org/10.1080/07370024.2014.921494

Fox, J., Ralston, R. A., Cooper, C. K., \& Jones, K. A. (2015). Sexualized avatars lead to women's self-objectification and acceptance of rape myths. Psychology of Women Quarterly, 39(3), 349-362. https://doi.org/10.1177/ 0361684314553578

Franc, E., Khazaal, Y., Jasiowka, K., Lepers, T., Bianchi-Demicheli, F., \& Rothen, S. (2018). Factor structure of the Cybersex Motives Questionnaire. Journal of Behavioral Addictions, 7(3), 601-609. https://doi.org/10.1556/ 2006.7.2018.67

Fraune, M. R., Oisted, B. C., Sembrowski, C. E., Gates, K. A., Krupp, M. M., \& Šabanović, S. (2020). Effects of robot-human versus robot-robot behavior and entitativity on anthropomorphism and willingness to interact. Computers in Human Behavior, 105, Article 106220. https://doi.org/ 10.1016/j.chb.2019.106220 
Gaudiello, I., Lefort, S., \& Zibetti, E. (2015). The ontological and functional status of robots: How firm our representations are? Computers in Human Behavior, 50, 259-273. https://doi.org/10.1016/j.chb.2015.03.060

Gratch, J., Wang, N., Gerten, J., Fast, E., \& Duffin, R. (2007). Creating rapport with virtual agents. Proceedings of the International Conference on Intelligent Virtual Agents. https://doi.org/10.1007/978-3-54074997-4_12

Guzman, A. L. (2018). What is human-machine communication anyway? In A. L. Guzman (Ed.), Human-machine communication: Rethinking communication, technology, and ourselves (pp. 1-285). Peter Lang. https://doi.org/10.3726/b14399

Guzman, A. L. (2020). Ontological boundaries between humans and computers and the implications for human-machine communication. HumanMachine Communication, 1, 37-54. https://doi.org/10.30658/hmc.1.3

Hauskeller, M. (2014). Kissingers and surrogates. In Sex and the posthuman condition (pp. 80-89). Palgrave Pivot. https://doi.org/10.1057/ 9781137393500_8

Herring, S. (1999). Interactional coherence in CMC. Journal of ComputerMediated Communication, 4(4), Article JCMC444. https://doi.org/10.1111/ j.1083-6101.1999.tb00106.x

Ho, A., Hancock, J., \& Miner, A. S. (2018). Psychological, relational, and emotional effects of self-disclosure after conversations with a chatbot. Journal of Communication, 68(4), 712-733. https://doi.org/10.1093/joc/ jqy026

Kahn, P. H., Reichert, A. L., Gary, H. E., Kanda, T., Ishiguro, H., Shen, S., Ruckert, J. H., \& Gill, B. (2011, March). The new ontological category hypothesis in human-robot interaction. In 2011 6th ACM/IEEE international conference on human-robot interaction (HRI) (pp. 159-160). IEEE. https://doi.org/10.1145/1957656.1957710

Kothgassner, O. D., Griesinger, M., Kettner, K., Wayan, K., VölklKernstock, S., Hlavacs, H., Beutl, L., \& Felnhofer, A. (2017). Real-life prosocial behavior decreases after being socially excluded by avatars, not agents. Computers in Human Behavior, 70, 261-269. https://doi.org/ 10.1016/j.chb.2016.12.059

Kukkonen, T. M., Binik, Y. M., Amsel, R., \& Carrier, S. (2010). An evaluation of the validity of thermography as a physiological measure of sexual arousal in a non-university adult sample. Archives of Sexual Behavior, 39(4), 861-873. https://doi.org/10.1007/s10508-009-9496-4

Lew, Z., Walther, J. B., Pang, A., \& Shin, W. (2018). Interactivity in online chat: Conversational contingency and response latency in computermediated communication. Journal of Computer-Mediated Communication, 23(4), 201-221. https://doi.org/10.1093/jcmc/zmy009

Li, J., Ju, W., \& Reeves, B. (2017). Touching a mechanical body: Tactile contact with body parts of a humanoid robot is physiologically arousing. Journal of Human-Robot Interaction, 6, 118-130. https://dl.acm.org/doi/ abs/10.5898/JHRI.6.3.Li

Lobato, E. J., Wiltshire, T. J., \& Fiore, S. M. (2013). A dual-process approach to understanding human-robot interaction. In Proceedings of the Human Factors and Ergonomics Society annual meeting (pp. 1263-1267). SAGE.

Lombard, M., \& Ditton, T. (1997). At the heart of it all: The concept of presence. Journal of Computer-Mediated Communication, 3(2), Article JCMC321. https://doi.org/10.1111/j.1083-6101.1997.tb00072.x

Lorenzo, G. L., Biesanz, J. C., \& Human, L. J. (2010). What is beautiful is good and more accurately understood. Physical attractiveness and accuracy in first impressions of personality. Psychological Science, 21(12), 1777-1782. https://doi.org/10.1177/0956797610388048

Luger, E., \& Sellen, A. (2016). "Like having a really bad PA": The gulf between user expectation and experience of conversational agents. In Proceedings of the $2016 \mathrm{CHI}$ conference on human factors in computing systems (pp. 5286-5297). ACM. https://doi.org/10.1145/2858036 .2858288

Mosher, D. L. (1988). Pornography defined. Journal of Psychology \& Human Sexuality, 1, 67-85. https://doi.org/10.1300/J056v01n01_06
Muehlenhard, C. L., \& Shippee, S. K. (2010). Men's and women's reports of pretending orgasm. Journal of Sex Research, 47(6), 552-567. https:// doi.org/10.1080/00224490903171794

Nass, C., Steuer, J., \& Tauber, E. R. (1994). Computers are social actors. In Proceedings of CHI'94 human factors in computing systems (pp. 72-78). ACM. https://doi.org/10.1145/191666.191703

Nass, C., \& Moon, Y. (2000). Machines and mindlessness: Social responses to computers. Journal of Social Issues, 56(1), 81-103. https://doi.org/ 10.1111/0022-4537.00153

Nguyen, M.-H. (2017, November 29). AI driven adult chatbots are being used for virtual boyfriends and girlfriends—and they keep getting smarter and sexier. Business Insider. https://www.businessinsider.com/virtualfriend-dirty-talking-adult-chatbots-2017-11

Nowak, K. L., Fox, J., \& Ranjit, Y. S. (2015). Inferences about avatars: sexism, appropriateness, anthropomorphism, and the objectification of female virtual representations. Journal of Computer-Mediated Communication, 20(5), 554-569. https://doi.org/10.1111/jcc4.12130

Oliveira, C., Laja, P., Carvalho, J., Quinta Gomes, A., Vilarinho, S., Janssen, E., \& Nobre, P. J. (2014). Predictors of men's sexual response to erotic film stimuli: The role of affect and self-reported thoughts. Journal of Sexual Medicine, 11(11), 2701-2708. https://doi.org/10.1111/jsm.12650

Pradhan, A., Findlater, L., \& Lazar, A. (2019). "Phantom friend" or "just a box with information": Personification and ontological categorization of smart speaker-based voice assistants by older adults. Proceedings of the ACM Conference on Human-Computer Interaction (no. 214). ACM. https://doi.org/10.1145/3359316

Reeves, B., \& Nass, C. I. (1996). The media equation: How people treat computers, television, and new media like real people and places. Cambridge University Press.

Richards, R., Coss, C., \& Quinn, J. (2017). Exploration of relational factors and the likelihood of a sexual robotic experience. In A. Cheok, K. Devlin, \& D. Levy (Eds.), Lecture notes in computer science: Vol. 10237. Love and sex with robots (pp. 97-103). Springer. https://doi.org/10.1007/978-3319-57738-8_9

Russell, J. A., Weiss, A., \& Mendelsohn, G. A. (1989). Affect grid: A singleitem scale of pleasure and arousal. Journal of Personality and Social Psychology, 57, 493-502. https://doi.org/10.1037/0022-3514.57.3.493

Safron, A. (2016). What is orgasm? A model of sexual trance and climax via rhythmic entrainment. Socioaffective Neuroscience \& Psychology, 6(1), Article 31763. https://doi.org/10.3402/snp.v6.31763

Sandoval, E. B., Brandstetter, J., Obaid, M., \& Bartneck, C. (2016). Reciprocity in Human-robot interaction: A quantitative approach through the Prisoner's Dilemma and the Ultimatum Game. International Journal of Social Robotics, 8(2), 303-317. https://doi.org/10.1007/s12369-0150323-x

Scheutz, M., \& Arnold, T. (2017). Intimacy, bonding, and sex robots: Examining empirical results and exploring ethical ramifications [Unpublished manuscript]. https://hrilab.tufts.edu/publications/scheutz2017 intimacy.pdf

Simon, W. \& Gagnon, J. H. (1986). Sexual scripts: Permanence and change. Archives of Sexual Behavior, 15(2), 97-120. https://doi.org/10.1007/ BF01542219

Suler, J. (2004). The online disinhibition effect. CyberPsychology \& Behavior, 7(3), 321-326. https://doi.org/10.1089/1094931041291295

Sundar, S. S., Bellur, S., Oh, J., Jia, H., \& Kim, H.-S. (2016). Theoretical importance of contingency in human-computer interaction: Effects of message interactivity on user engagement. Communication Research, 43 , 595-625. https://doi.org/10.1177/0093650214534962

Szczuka, J. M., \& Krämer, N. C. (2017). Not only the lonely-How men explicitly and implicitly evaluate the attractiveness of sex robots in comparison to the attractiveness of women, and personal characteristics influencing this evaluation. Multimodal Technologies and Interaction, 1(1), Article 3. https://doi.org/10.3390/mti1010003 
Szczuka, J. M., \& Krämer, N. C. (2018). Jealous 4.0? An empirical study on jealousy-related discomfort of women evoked by other women and gynoid robots. Paladyn, Journal of Behavioral Robotics, 9, 323-336. https:// doi.org/10.1515/pjbr-2018-0023

Szczuka, J. M., \& Krämer, N. C. (2019). There's more to humanity than meets the eye: Differences in gaze behavior toward women and gynoid robots. Frontiers in Psychology, 10, Article 693. https://doi.org/10.3389/ fpsyg.2019.00693

Szczuka, J. M., Hartmann, T., \& Krämer, N. C. (2019). Negative and positive influences on the sensations evoked by artificial sex partners: A review of relevant theories, recent findings, and introduction of the Sexual Interaction Illusion Model. In Y. Zhou \& M. H. Fischer (Eds.), AI love you: Developments in human-robot intimate relationships (pp. 3-19). Springer International. https://doi.org/10.1007/978-3-030-19734-6_1

Toledano, R., \& Pfaus, J. (2006). The Sexual Arousal and Desire Inventory (SADI): A multidimensional scale to assess subjective sexual arousal and desire. Journal of Sexual Medicine, 3(5), 853-877. https://doi.org/ 10.1111/j.1743-6109.2006.00293.x

Van Ouytsel, J. V., Walrave, M., Ponnet, K., \& Temple, J. R. (2018). Sexting. In T. K. Shackelford \& V. A. Weekes-Shackelford (Eds.), Encyclopedia of evolutionary psychological science (pp. 1-3). Springer International. https://doi.org/10.1007/978-3-319-16999-6_218-1
Verhagen, T., Van Nes, J., Feldberg, F., \& Van Dolen, W. (2014). Virtual customer service agents: Using social presence and personalization to shape online service encounters. Journal of Computer-Mediated Communication, 19(3), 529-545. https://doi.org/10.1111/jcc4.12066

von der Pütten, A. M., Krämer, N. C., Gratch, J., \& Kang, S.-H. (2010). "It doesn't matter what you are!" Explaining social effects of agents and avatars. Computers in Human Behavior, 26(6), 1641-1650. https:// doi.org/10.1016/j.chb.2010.06.012

Weinstein, A. M., Zolek, R., Babkin, A., Cohen, K., \& Lejoyeux, M. (2015). Factors predicting cybersex use and difficulties in forming intimate relationships among male and female users of cybersex. Frontiers in Psychiatry, 6, Article 54. https://doi.org/10.3389/fpsyt.2015.00054

Youn, G. (2006). Subjective sexual arousal in response to erotica: Effects of gender, guided fantasy, erotic stimulus, and duration of exposure. Archives of Sexual Behavior, 35(1), 87-97. https://doi.org/10.1007/s10508-0068997-z

Received October 07, 2019 Revision received April 12, 2020

Accepted April 18, 2020 